\title{
Effectivity of One Session Charcoal Hemoperfusion Treatment in Severe Car- bamazepine Poisoning
}

\author{
Yasemin Isik ${ }^{1, *}$, Lokman Soyoral ${ }^{2}$, Sevdegul Karadas ${ }^{3}$, Habib Emre ${ }^{4}$, Muhammed Bilal \\ Cegin $^{5}$, Ugur Goktas ${ }^{5}$ \\ ${ }^{1}$ Department of Anesthesiology and Intensive Care, Medical Faculty, Yuzuncu Yil University, Van, Turkey \\ 2 Department of Anesthesiology and Intensive Care, State Hospital, Van, Turkey \\ 3 Department of EmergencFaculty, Yuzuncu Yil University, Van, Turkey \\ 4 Department of Nephrology, Medical Faculty, Yuzuncu Yil University, Van, Turkey \\ 5 Department of Nephrology, Medical Faculty, Yuzuncu Yil University, Van, Turkey \\ ${ }^{*}$ Corresponding author: Yasemin Isik, Department of Anesthesiology and Intensive Care, Medical Faculty, Yuzuncu Yil University, Van, Turkey. Tel: +90-4322151669, E-mail: yasemi- \\ nmd@yahoo.com.
}

Received: August 01, 2012; Revised: January 07, 2013; Accepted: July 06, 2013

\begin{abstract}
A carbamazepine intoxication with suicide attempt is a relatively common clinical problem that presenting with coma, respiratory depression, arrhythmia, hemodynamic instability and even death. We report a case of severe carbamazepine poisoning that was successfully treated with one session charcoal hemoperfusion. On admission, the patient was comatose and required ventilator support. Hemoperfusion with coated activated charcoal successfully decreased the serum carbamazepine concentration from $45 \mu \mathrm{g} \mathrm{mL}{ }^{-1}$ to $21 \mu \mathrm{g}$ $\mathrm{mL}^{-1}$ within $2 \mathrm{~h}$, with subsequent clinical improvement.
\end{abstract}

Keywords: Carbamazepine; Toxicity; Hemoperfusion

\section{Introduction}

A carbamazepine (CBZ) is a widely prescribed drugs that using in the treatment of epilepsy, neuralgic pain syndromes and certain affective disorders. A carbamazepine intoxication with suicide attempt is a relatively common clinical problem that presenting with coma, respiratory depression, arrhythmia, hemodynamic instability and even death (1-3). The mortality rate due to / CBZ toxicity is around 13\% (3). The adult therapeutic CBZ plasma level is between 4 and $12 \mu \mathrm{g} \mathrm{mL}{ }^{-1}(4)$. Several therapeutic interventions including charcoal hemoperfusion (HP), hemodialysis (HD), hemodiafiltration and plasma exchange have been performed for the treatment of acute CBZ intoxication $(5,6)$. However, overall multiple-dose activated charcoal HP seems to the most effective and popular treatment option $(7,8)$. We report a case of severe carbamazepine poisoning who was treated with one session charcoal hemoperfusion.

\section{Case Report}

A 19-year-old girl was brought to an emergency room 4 hours after ingestion of 100 tablets CBZ (each CBZ tablet was $400 \mathrm{mg}$ ). She was transferred to intensive care unit 6 hours after the ingestion. On admission, in the physical examination, she was unconscious but responsive to pain stimuli, Glasgow coma score (GCS): 8 , her blood pressure: 110/55 mmHg, pulses: $120 / \mathrm{min}$, temperature: $36.7^{\circ} \mathrm{C}$ and respiratory rate: $20 / \mathrm{min}$. The breath sounds were coarse and heart sounds were rhythmic and tachycardic. Other system examinations were normal. A Gastric lavage was performed and an activated charcoal was given once before arrival to the hospital. Isotonic solution (\%0.9 NaCl) was administered IV to the patient. On admission, her CBZ level was $53 \mu \mathrm{g} \mathrm{mL}^{-1}$. Laboratory tests during admission and follow-ups are shown in Table1. On the eight hours after ingestion evaluation, she was still comatose and was intubated. Patient underwent ventilation with Synchronized intermittent mandatory ventilation (SIMV) mode: pressure control ventilation, $12-14 \mathrm{~cm} \mathrm{H} 2$ O; inspiratory time, $0.8 \mathrm{~s}$; triggering sensitivity, $0.6 \mathrm{~L} \mathrm{~min}^{-1}$; positive endexpiratory pressure, $4 \mathrm{~cm} \mathrm{H} 2 \mathrm{O}$; and $\mathrm{FiO} 2$ :40-50\%. The hemoperfusion cartridge was not readily available in our instution at the beginning, so we initially administered hemodiafiltration for 6 hours period. After providing hemoperfusion cartridge, $4 \mathrm{~h}$ of charcoal-HP was administered. The blood flow rate was 200 to $300 \mathrm{~mL} \mathrm{~min}^{-1}$ and the dialysate flow rate: $300-500 \mathrm{~mL} \mathrm{~min}^{-1}$. These rates

Implication for health policy/practice/research/medical education:

We conclude that one session charcoal-hemoperfusion is a safe and effective alternative treatment for life-threatening severe carbamazepine intoxication. Charcoal-hemoperfusion is preferred to prevent further seizures, shorten mechanical ventilation time and intensive care unit time, and decrease risk of infectious or neurological complications.

Copyright (C) 2013, Iranian Red Crescent Medical Journal; Licensee KowsarKowsar Ltd. This is an Open Access article distributed under the terms of the Creative Commons Attribution License (http://creativecommons.org/licenses/by/3.0), which permits unrestricted use, distribution, and reproduction in any medium, provided the original work is properly cited. 
varied with the hemodynamic chancing of the patient and regarding blood gases analyses to eliminate more drugs from blood. Heparin anticoagulation was initiated with a $1000 \mathrm{U}$ bolus, followed by a continuous infusion of $750 \mathrm{U} \mathrm{h}^{-1}$, and was adjusted as needed to achieve a partial thromboplastin time of 80 to 100 seconds. Repeated administration was not needed after $4 \mathrm{~h}$ charcoal-HP. The blood CBZ level just after the procedure was $20 \mu \mathrm{g} \mathrm{mL}{ }^{-1}$ , and it declined to $8 \mu \mathrm{g} \mathrm{mL}^{-1}$ at 72 hours of the admission. The follow-up CBZ levels are summarized in Table 2. At the end of the procedure, she was extubated. She was discharged from hospital on the fourth day.

\begin{tabular}{lllll}
\hline Table 1. Patients' Laboratory Tests & & & \\
\hline & 1. day & 2. day & 3. day & 4. day \\
\hline Glucose(mg/dL) & 138 & 184 & 112 & 107 \\
Creatinine(mg/dL) & 0,7 & 0,3 & 0,5 & 0,5 \\
ALT(U/L) & 16 & 18 & 16 & 20 \\
Haemoglobin(g/dL) & 12 & 8,4 & 9,9 & 10,2 \\
Platelet $(\mathbf{1 0 3})$ & 186 & 119 & 97 & 127 \\
INR & 1,48 & 2,37 & 1,6 & 1,2 \\
Potassium(mmol/L) & 3,9 & 2,4 & 2,7 & 4 \\
Calcium(mg/dL) & 8,1 & 7,9 & 8,3 & 8,2
\end{tabular}

\begin{tabular}{|c|c|c|c|c|c|c|c|c|c|}
\hline Before HDF procedure & After HDF procedure & Before Charcoal-HP procedure & 1.h & 2. h & 4. h & 12.h & 24.h & 48.h & 3.day \\
\hline 53 & 45 & 45 & 19 & 21 & 20 & 20 & 19 & 19 & 8 \\
\hline
\end{tabular}

\section{Discussion}

CBZ intoxication can cause seizures, coma, arrhythmias and even death (1-3). There is a complex distribution and metabolism of CBZ. CBZ is slowly absorbed from gastrointestinal system and also has inhibitory action on bowel motility. Thus the peak CBZ level is accomplished within 10 to 30 hours following oral ingestion. The oral CBZ absorption rate is around $70-95 \%$, the serum CBZ-protein binding rate is $80-85 \%$ with a moderately large volume of distribution. During acute intoxication, CBZ pharmacokinetic features can interfere its rapid elimination from the body $(5,9)$. The multiple dose administration of activated charcoal increase CBZ clearance from the body by interfering with entero-enteric circulation of CBZ. If serum CBZ concentration is greater than $40 \mathrm{mcg} / \mathrm{mL}$, serious complications including coma, respiratory depression, seizures, and ventricular arrhythmias can occur (1, 2). The measurement of the primary metabolite CBZ-10, 11-epoxide is not readily available in our institution, so we measured total CBZ plasma concentration. In our case, the CBZ level was $53 \mu \mathrm{g} \mathrm{mL}^{-1}$ on the admission. She had sinus tachycardia and was intubated due to development of respiratory depression. The hemoperfusion cartridge was not readily available in our institution; therefore we applied four hours hemodiafiltration. After four hours hemodiafiltration, the CBZ level was decreased to $45 \mu \mathrm{g}$ $\mathrm{mL}^{-1}$. Then four hours-charcoal hemoperfusion was administered. A charcoal HP was preferred as it has been the most commonly recommended intervention for severe acute CBZ. In the previous study, hemoperfusion was shown to be superior to hemodialysis (10). Choarcoal-HP can reduce serum CBZ concentrations by 25 to $50 \%$ (8, 10-12). In severe cases, the artificial ventilation may be needed for several days after the hemoperfusion (10-12). The persistence of neurologic effects may be related to absorption of the medication from the gut.(10, 12) Our patient was extubated after one session hemoperfusion and no neurological complication was observed. CBZ level was not diminished after 1 hour that might be related to reduced charcoal absorptive capacity after the first hour with prolonged treatment, reflecting cartridge saturation.

The hemoperfusion-related side effects are hypocalcaemia, thrombocytopenia, coagulopathies, and hypothermia. The hypocalcaemia, hypokalemia, thrombocytopenia and coagulopathy were seen in our patient. The hypocalcaemia and hypokalemia were replaced but treatment did not need for thrombocytopenia and coagulopathy. However, all the parameters were normalized 4 days following the treatment (Table 1 ).

\section{Conclusions}

We conclude that one session charcoal-hemoperfusion is a safe and effective alternative treatment for life-threatening severe carbamazepine intoxication. Complications by charcoal-hemoperfusion should be considered. Charcoal-hemoperfusion is preferred to prevent further seizures, shorten mechanical ventilation time and intensive care unit time, and decrease risk of infectious or neurological complications.

\section{Acknowledgements}

None declared.

\section{Authors' Contribution}

None declared.

\section{Financial Disclosure}

None declared. 


\section{Funding/Support}

None declared.

\section{References}

1. Hojer J, Malmlund HO, Berg A. Clinical features in 28 consecutive cases of laboratory confirmed massive poisoning with carbamazepine alone. J Toxicol Clin Toxicol. 1993;31(3):449-58.

2. Spiller HA, Krenzelok EP, Cookson E. Carbamazepine overdose: a prospective study of serum levels and toxicity. J Toxicol Clin Toxicol.1990;28(4):445-58.

3. Schmidt S, Schmitz-Buhl M. Signs and symptoms of carbamazepine overdose. J Neurol.1995;242(3):169-73.

4. Lai MW, Klein-Schwartz W, Rodgers GC, Abrams JY, Haber DA, Bronstein AC, et al. 2005 Annual Report of the American Association of Poison Control Centers' national poisoning and exposure database. Clin Toxicol (Phila). 2006;44(6-7):803-932.

5. Duzova A, Baskin E, Usta Y, Ozen S. Carbamazepine poisoning: treatment with plasma exchange. Hum Exp Toxicol. 2001;20(4):175-7.
6. Goktas U, Kati I, Yuce HH. Management of a severe carbamazepine overdose with continuous venovenous hemodiafiltration. Am J Emerg Med. 2010;28(2):260 e1-2.

7. Charcoal Hemoperfusion in the Treatment of two Cases of Acute Carbamazepine Poisoning. Clinical Toxicology.1984;22(4):349-362.

8. Deshpande G, Meert KL, Valentini RP. Repeat charcoal hemoperfusion treatments in life threatening carbamazepine overdose. Pediatr Nephrol.1999;13(9):775-7.

9. Vale JA, Krenzelok EP, Barceloux GD. Position statement and practice guidelines on the use of multi-dose activated charcoal in the treatment of acute poisoning. American Academy of Clinical Toxicology; European Association of Poisons Centres and Clinical Toxicologists. J Toxicol Clin Toxicol.1999;37(6):731-51.

10. Schuerer DJ, Brophy PD, Maxvold NJ, Kudelka T, Bunchman TE. High-efficiency dialysis for carbamazepine overdose. J Toxicol Clin Toxicol. 2000;38(3):321-3.

11. Nilsson C, Sterner G, Idvall J. Charcoal hemoperfusion for treatment of serious carbamazepine poisoning. Acta Med Scand. 1984;216(1):137-40.

12. Gary NE, Byra WM, Eisinger RP. Carbamazepine poisoning: treatment by hemoperfusion. Nephron. 1981;27(4-5):202-3. 